\title{
Inclusive Teaching With Digital Technology: Supporting Literacy Learning in Play-Based Kindergartens
}

Monica McGlynn-Stewart, Leah Brathwaite, Lisa Hobman, Nicola Maguire, Emma Mogyorodi, and Yeh Uhn Park

\begin{abstract}
Young children who are English Language Learners or have special learning needs can find it difficult to communicate in kindergarten classrooms. Open-ended tablet applications offer multi-modal tools for these children to communicate their ideas, engage with others, and demonstrate and develop their knowledge and skills. They position students as the producers and creators of the literacy content. Using pedagogical strategies such as effective routines, opportunities to collaborate and share with peers, and modelling, kindergarten educators can employ open-ended iPad apps to support the literacy and digital learning of children who are English Language Learners or who have special learning needs.
\end{abstract}

\section{Background}

Young children who are English language learners (ELLs) or who have special learning needs (SLNs) can have a difficult time communicating their knowledge and skills in typical early learning classrooms. They can be constrained by tools and practices that privilege able-bodied children who speak the language of instruction and who are strong in formal academic skills. Typically, early years educators assess children through observation, paper-and-pencil tasks, or oral questioning. For children who are ELLs, or who have SLNs, these types of assessments can fail to reveal an accurate picture of the range and depth of their interests and abilities. Educators and peers may view these children in stereotypical ways due to a focus on traditional academic tools and skills. This can, in turn, negatively affect the children's self-image and may lead to social isolation in the classroom. Open-ended iPad apps can offer alternative visual and auditory tools for children who are ELLs or have SLNs to communicate their ideas, engage with others, and demonstrate and develop their knowledge and skills.

This paper reports on the first two years (2015/2016-2016/2017) of a three-year a research study examining the use of open-ended iPad apps to support young children's literacy learning in 14 full-day kindergarten classrooms in Ontario (ages three to six). Literacy in this study is defined broadly, as meaning-making in multiple forms including visual, oral, print, and digital. Literacy activities are often social and collaborative in nature, and are integrated into play and other content areas such as Mathematics and Science. The curriculum for kindergarten in Ontario, The Kindergarten Program (Ontario Ministry of Education, 2016), advocates a play-based approach to learning and teaching:

LEARNing Landscapes | Autumn 2017, Vol. 11 No. 1 | 199 
Play is a vehicle for learning and rests at the core of innovation and creativity. It provides opportunities for learning in a context in which children are at their most receptive. Play and academic learning are not distinct categories for young children, and learning and doing are also inextricably linked for them. It has long been acknowledged that there is a strong link between play and learning for young children. (Ontario Ministry of Education, 2016, p. 18)

The classrooms in the study are situated in two large urban school boards in Ontario. The children come from families that are culturally, linguistically, and economically diverse. Children enter the kindergarten program in the year that they turn four, and stay for two years. The iPad apps used in this study, 30 Hands and Explain Everything, are open-ended. They offer a range of visual recording options including drawing, photo, and video functions, as well as audio recording. There is no content other than a few background scenes, and they are not designed to teach any specific skills. These open-ended apps complement a play-based approach to learning and teaching. All children, including those who are ELLs or who have SLNs, were able to explore and document their learning in ways that met their individual learning needs through the multimodal tools provided in the iPad apps. The research question that governed this study was: How do children who are English Language Learners or who have Special Learning Needs explore, document, and share their thinking with open-ended iPad apps in a play-based kindergarten?

\section{Literature Review}

Several recent studies describe how mobile digital technology (DT), such as smartphones and tablet computers, are being used to support young children's literacy learning at home and at school, and to create a school-to-home link (Neumann, 2016; Radesky, Schumacher, \& Zuckerman, 2015; Wong, 2015; Blagojevic, Brumer, Chevalier, O'Clair, \& Thomes, 2012). While some studies have examined the use of e-Books, e-games, digital drawing pens (Lee, Wu, \& Chen, 2017), augmented reality toys (Yilmaz, 2016) and learn-to-read apps, studies that report on the use of open-ended iPad apps in school environments are emerging (e.g., Fleer, 2014; Herro, 2015). In fact, several studies (e.g., Rowsell \& Harwood, 2015; Falloon \& Khoo, 2014) illustrate the dynamism with which DT is being explored in early learning classrooms as a way to redefine literacy acquisition, expression, development, and consolidation.

The use of iPads and open-ended apps expands the range of modes that young children have available as they make meaning. Rather than just drawing and writing, they have access to photography, video, audio, clip art, and so forth, which they can use in isolation or in combination (Rowsell, 2017). This multimodal approach to literacy helps to reveal children's interests, motivations, and different pathways to literacy (Kress, 1997). As Gee (2005) reminds us, new technology allows for thinking and making meaning differently, "learning in a new domain... requires the learner to take on a new identity" (p. 34). Through open-ended mobile apps, young children can interweave the many physical and digital texts in their lives to represent what is meaningful to them (Burnett, Merchant, Pahl, \& Rowsell, 2014). Young children need time and space to engage with the multiplicity of literacy texts that they encounter. Play is a necessary part of this (MacKey, 2011). Through play, children can experience the thoughts, feelings, and behaviours that ground different identities, informed by the texts they have experienced. 
Open-ended mobile tablet apps can offer one way to engage in, document, and reflect on meaningmaking play activities.

The multimodal affordances of open-ended iPad apps are particularly effective in supporting the literacy learning of children who have special learning needs (SLNs) or who are English Language Learners (ELLs). Two recent studies highlight the positive effects of multimodal DT for children with Autism Spectrum Disorder (ASD). Flores and colleagues (2012) found that using iPad apps with children who had ASD and limited verbal interaction increased the amount of their communication and made communication faster and easier. Moreover, both the students and their teachers reported enjoying the iPads more than traditional communication methods for children with ASD such as the Picture Exchange Communication System (PECS). Oakley, Howitt, Garwood, and Durack (2013) found that children with ASD increased both their engagement and the level of their literacy achievement when using DT to create multimodal texts.

Children who are ELLs have a better chance of performing well academically when their home languages are valued within the classroom, and when they are offered a culturally responsive curriculum and pedagogy to meet their needs (UNESCO, 2011). Rodriguez (2010) suggests children's home languages can be supported by educators in early years programs with attention to a few specific strategies, including being informed about the benefits of using and maintaining home languages, encouraging the use of the home language at home, and providing learning materials that reflect the diverse home languages of the children in the program. In fact, when children are given the opportunity to use their home language in addition to learning the majority language, they show cognitive advantages in terms of cross-cultural understanding and communication, problem solving, comprehension and verbal flexibility (Nicoladis, Charbonnier, \& Popescu, 2016). Open-ended iPad apps can provide support for children to consolidate and enhance their home language while continuing to develop their proficiency in the language of instruction.

There are voices urging caution when using DT with young children (e.g., NAEYC, 2012; Radesky et al., 2015; Council on Communication and Media, 2016), yet these same researchers also champion the potential of DT for children's learning when it is used in ways that are active and interactive, and support an inquiry stance to learning. When used intentionally, new digital literacies can help educators teach students to question, construct theories, and develop the skills needed for active global citizenship (Wimmer, Skramstad, \& Khan, 2012). The increasing complexity of how we communicate as a global society means that we need highly skilled teachers who have a broad definition of literacy, can incorporate digital technologies (DT) into their learning programs, and recognize that literacy is rapidly evolving. However, current pre-service and in-service professional learning offer little guidance on the appropriate use of DT in early years programs. 


\section{Methodology}

This paper reports on the first two years (2015/2016-2016/2017) of a three-year study of 14 kindergarten classrooms in Ontario as they used open-ended tablet apps (30 Hands and Explain Everything) in their play-based programs. The tablet apps were used most often during open-ended activity time, but also during outdoor play and more focused literacy activities. Most classrooms had two educators (27 educators in year 1 in total, and 25 educators in year 2 in total). The educators, Registered Early Childhood Educators (RECEs) and Ontario Certified Teachers (OCTs), were all interviewed before the study began to determine their experiences with DT and their attitudes towards using DT with young children. At the end of year one, they were interviewed again to see if their attitudes towards using DT with young children had changed, and to learn about what they perceived to be the challenges and benefits of using the tablet apps in their programs to support literacy learning. At the beginning of year two, they completed a questionnaire on similar topics, and at the end of year two they were interviewed again. All educators attended a focus group each year. The interviews were recorded and transcribed, and detailed notes were taken during the focus groups. Classrooms were observed biweekly using participant observation. Research team members also worked with small groups of children during these biweekly visits to support them in their use of the apps. Students had individual accounts within the iPad apps where they could archive their slideshows. Samples of student digital slideshows were collected and analyzed. All children's names are pseudonyms.

\section{Findings}

\section{Support for English Language Learners}

English language learners (ELLs) and children with special learning needs (SLNs) often need extra support to communicate their thinking in educational settings. For ELLs in this study, open-ended tablet apps supported them in three ways: 1) they allowed children to practice their English skills and consolidate their skills in their first language; 2) they enabled children to communicate their ideas and showcase their skills; and 3) they provided opportunities for children to become integrated into the classroom community.

ELLs in several classrooms in our study practiced their English skills using the open-ended apps on the iPads. They would take an iPad and record themselves speaking English in a quiet corner of the class. They would listen back to their recordings, often erasing them and rerecording their voice. Both the ability to practice in private and to erase and rerecord seemed to be important and motivating factors. The iPad apps provided a safe opportunity to take the risks necessary to become proficient in a new language. The children were not singled out for language practice, as other children were also using iPads for many purposes around the room. They were able to choose what they wanted to say, get immediate, private feedback through listening to their recording, and were able to assess their own progress. This provided a more natural and less stressful opportunity to practice their skills in a new language than being asked to speak in front of others or to complete specific language exercises. 
The following slideshow was made by Omar, an ELL, who created a tower out of magnetic geometric tiles. He used the iPad app 30 Hands to independently photograph his tower and then audio-record his description of his creation and of the process. He is clearly proud of both the finished product and the fact that the created it on his own. In his recording, the sounds of a busy classroom can be heard as well as his explanation, "This is a picture of a big tower. I do it by myself with no help."

\section{https://drive.google.com/open?id=0B-UwQzpzAxH2TVJZcWJGSUpJYXBIUzdQNDBrTFJQcnRURjFR}

Because Omar was able to practice and then rerecord what he wanted to say in a private space in the classroom, he was able to complete an accurate and expressive account of his building activity. When his teacher found the slideshow on the iPad later, she was surprised and pleased by the level of sophistication of his English and his positive attitude towards his work.

In addition to providing opportunities to practice and enhance their English skills, several educators reported that ELLs used the iPad apps to consolidate their use of their home languages. Children created slideshows in their home language, either on their own or with peers who spoke the same language. This allowed them to enhance their home language and strengthen a home-school connection, which is vital for multilingual children. Aisha, for example, created a flower with classroom materials, asked a research team member to hold it while she photographed it with the iPad, then recorded herself singing in her language. She called it her language song:

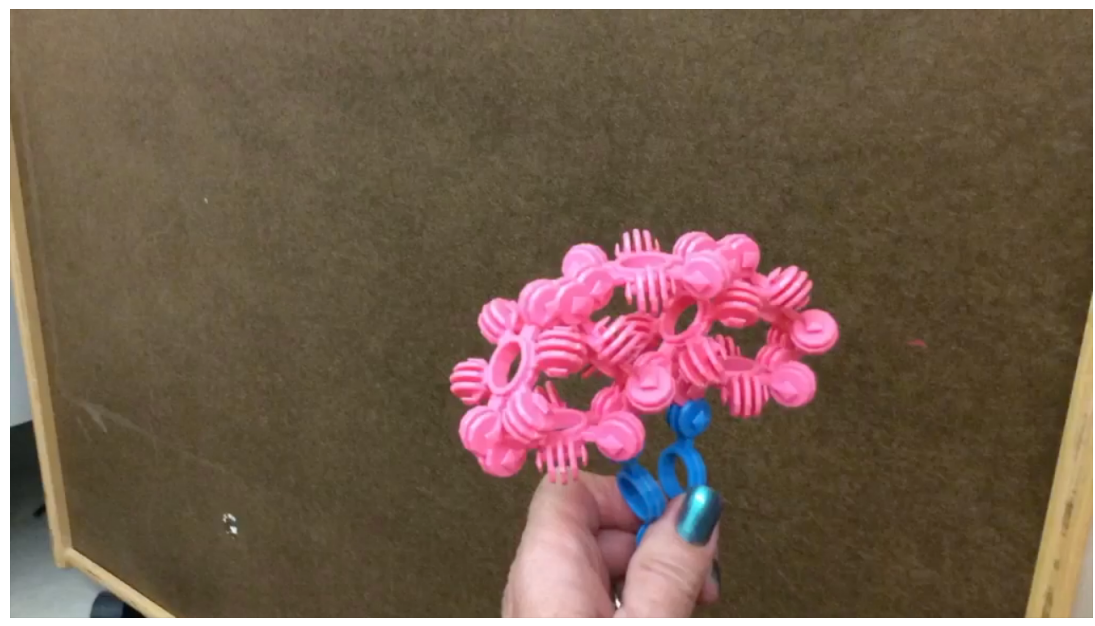

Fig. 1: Aisha's flower

\section{https://drive.google.com/open?id=0B-8zbVoc9owiLW05NDdIZk1JRUU}

She effortlessly recorded her voice in both English and her home language using classroom materials as a prop, and then proudly played the slideshow for her mother at the end of the day. The iPad app also allowed another student, Fatima, to create a link between her home language and English, and between the classroom environment and her family. 
For other children, the iPad apps provided an opportunity to speak with others who shared their home language as well as practice English with other ELLs. At the end of the first year of the study, one educator remarked that two Mandarin-speaking children with limited English realized that it was acceptable to speak in their own language as well as to continue to learn English. When they first used an iPad in the class, the children took it to a quiet corner and videotaped each other saying a few short phrases in Mandarin. Later they photographed their block structures and audio-recorded longer passages in Mandarin. The educator described the children's reaction and the positive consequences:

The two little guys would get talking in their first language on [30 Hands], they thought that was quite interesting. They were amazed when they could see what happens. They played it back and they thought it was quite funny. You know, but it was not just laughter, it was more about communication in Chinese because prior to that they were talking in English and didn't know they could speak Chinese in class. So I think that once they realized they could, they seemed to flourish. Their English has also developed as a result of it so that was nice too. (Kindergarten Educator, Spring 2016)

These two children initially believed they could only speak in their limited English, and were therefore constrained in their ability to communicate in class. Through the use of the iPad apps, they realized that they could communicate in their first language to other Mandarin-speaking students. They went from being shy and quiet students to being animated and more fully involved in activities around the classroom. This, in turn, led to the development of their oral English skills.

The second way that the open-ended iPad apps supported ELLS was by giving them the ability to effectively communicate their knowledge and skills to their educators and peers in spite of their limited proficiency in English. The open-ended apps allowed the children to use drawing, photography, and video in addition to text or audio to communicate their ideas. Several educators reported finding slideshows made by ELLs on the iPads that contained evidence of interests and digital skills that had been previously unknown to the educators. For example, one educator reported that when she was checking the iPads, she found Javeen's slideshow containing several drawings of a vacation he had taken with this family, including audio recordings with simple descriptions of the drawings. The educator had not known he had taken this vacation, or that he had the digital or storytelling skills to independently create a slideshow. The slideshow provided the opportunity to learn more about the child's abilities and his activities outside of school. This knowledge provided the foundation for a meaningful discussion, an important part of learning a new language. It also enabled the educator to build on this new knowledge in her planning, and to showcase and celebrate Javeen's accomplishments with the rest of the class.

Children who were ELLs were also able to share their interests and skills with their peers using the iPad apps. In some of the kindergarten classrooms, sharing digital slideshows of documented work became a regular part of classroom group time. Children would build with blocks or other materials, paint pictures, or draw or write on paper and then photograph their work on the iPad apps and audio-record a description. Some also created drawings on the iPad and narrated fictional stories using the iPad apps. They would then show the digital documentation they had made at group time, and either explain what they were showing or play the audio of their previously recorded explanation. This would be followed 
by questions from educators and peers. Several ELLs, who were too shy to speak at group time generally, were confident enough to share their documented work on the iPad. When they were asked questions about their work, many were not able to give long explanations of their iPad creations, but could answer "yes" or "no" to their peers' questions. In this way, the iPad apps allowed them to participate in the classroom routine of sharing from which their limited English has excluded them. As one educator explained, having the time to reflect on their learning, gather their thoughts, and rerecord if needed, enabled them to overcome the "performance anxiety" inherent in sharing in front of a group. She explained:

Just seeing some of the kids that wouldn't normally explain their thinking so well, they were really stopping to think now after they did something, "What did I do?" So it was a chance for them to start to really talk about it. And even if they were too shy to maybe explain it or they couldn't get their thoughts together in a class setting, they could use the iPad and talk about what they did. And we figured out how to even re-record so they knew that if what they were saying wasn't working out they could try again. The ones who didn't have much English they could still say little things that were helpful in explaining their thinking...And it built their confidence for sure. So I think that helped with the language and the confidence building. (Kindergarten educator, June 2017)

The third way that the open-ended iPad apps supported ELLs was by functioning as an integration tool in the classroom. When children do not speak the language of instruction, they can become isolated in a classroom setting. In this study, the iPads functioned as a medium of introduction and integration for ELLs. Several of the ELLs were already proficient in the use of iPad apps when they joined their class, or they quickly became proficient. This skill attracted other children to them. For example, in the second year of the study, one educator told the story of a new child in the class, Bentley, who was not a native English speaker and who had rarely spoken in class. Bentley watched other children on the iPad and quickly became one of the most adept children in the class. The other children wanted to be close to him to see what he could show them. He was a patient and effective teacher and soon was engaged in iPad collaborative projects with other children. This increased Bentley's social status in the classroom and he was sought out by other children at other times of the day. The iPad apps allowed him to use his digital skills to share ideas, mentor his peers, collaborate, and socialize even though he did not share a common language with the other children in the class. For the ELLs in this study, the iPad apps supported them in their academic and social integration into the kindergarten classrooms.

\section{Support for Children With Diverse Learning Needs}

Within the 14 classrooms in the study, there were several children who had special learning needs that ranged from mild learning challenges or delays to significant cognitive and/or physical challenges. There were three main ways that the use of the open-ended iPad apps supported the learning of these children: 1 ) the open-ended nature of the apps meant that there were multiple entry levels for communication from simple to sophisticated; 2) the multiple modes available on the iPad apps (e.g., visual, audio, text) allowed children to communicate using their strengths and supported them in their areas of challenge; and 3) the iPads supported the integration of children with special learning needs into the classroom. 
The open-ended apps used in this study, 30 Hands and Explain Everything, can be used to create very simple drawings or photos or more complex multimodal creations. Children were able to use the apps at their individual ability levels and could progress at their own pace. Children in the study who faced learning challenges were able to communicate their ideas in ways that helped them to overcome the barriers they faced with traditional paper-and-pencil tasks. For example, children could take a simple photo of the room, themselves, a classmate, or a creation they had made. The photo below was taken with an iPad by the artist, a four-year-old student. She was able to independently and effectively document her artistic creation as a digital slide without recourse to speaking, reading, or writing.

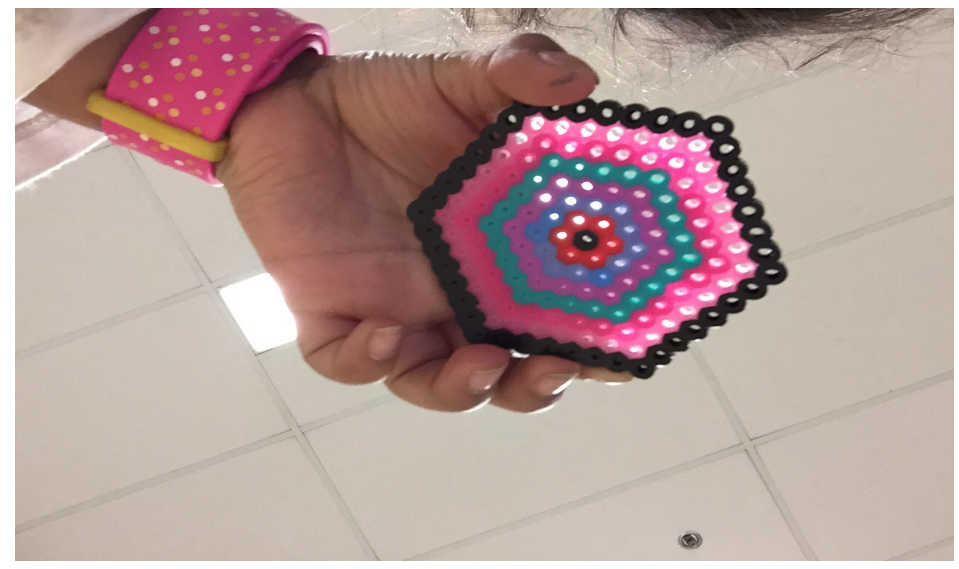

Fig. 2: Photo taken with iPad

Children could also choose a blank slide and use the drawing tools to experiment with lines and colours, or they could draw a scene such as the one below. This child has drawn a scene with a rainbow over a field of grass with an oversized, smiling insect. It certainly communicates a story with emotion and energy, but without the use of audio or text.

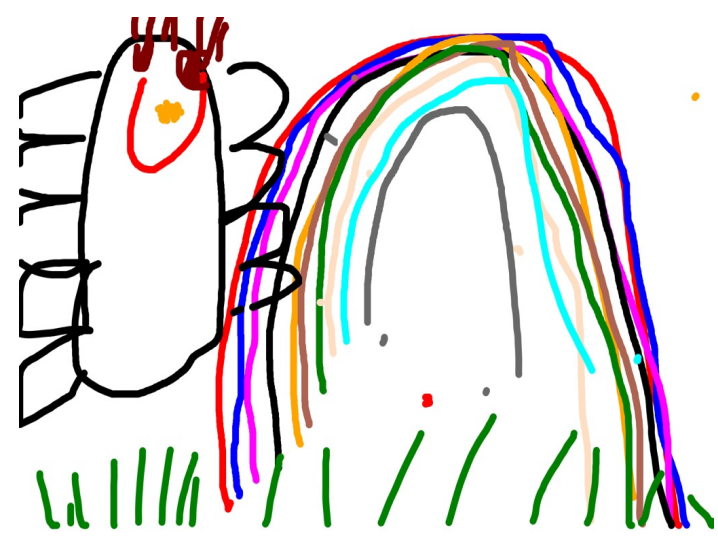

Fig. 3: Rainbow with smiling insect 
Children who were more technically skilled could use a combination of tools to create a slideshow like the one below. For this slideshow, the child chose the desert background, drew a scene from the movie Star Wars, and then audio-recorded himself humming a song from the movie. As in the previous examples, this quite sophisticated digital slideshow did not require advanced traditional academic skills in order to communicate a strong message, but the child clearly displays sophisticated digital skills.

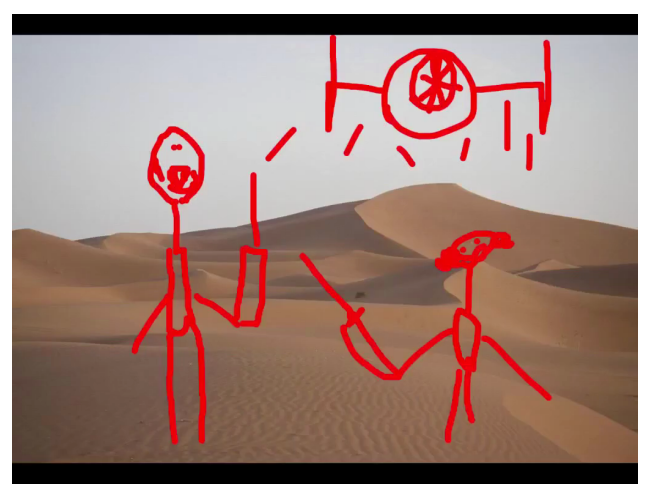

Fig. 4: Scene from Star Wars

\section{https://drive.google.com/drive/folders/0B-GF9ZCaXHvLc1VHb3lwY25Xb1E}

Children who were at an early stage of formal school literacy accomplishment or who had a learning challenge were able to use the tools in the open-ended apps at a level that matched their needs and abilities.

The second way that the apps supported children with special learning needs was through the multiple modes that were available on the iPads. The apps provided tools that allowed the children to remove barriers that they faced and allowed them to express their ideas more powerfully. Children who had a range of challenges were able to express their ideas using the multiple modes within the apps. Those who had challenges with fine motor control, and therefore found it difficult to draw or write, could audio-record their ideas. Children who had difficulty speaking or encoding their ideas in text could communicate visually through photos, videos, and/or drawings.

For example, for Connor, a child with autism spectrum disorder, the iPad app modes of drawing and audio-recording supported him in his areas of challenge and gave him a positive voice in the classroom. Before he used the iPad apps, Connor spoke very little and had minimal social interactions with other children. He was often perceived as having disruptive and challenging behaviour in the classroom, and he was reluctant to try new things. Using the iPad app 30 Hands, he communicated his ideas through drawing on blank slides and recording simple stories, which he proudly shared with others. The open-ended iPad app allowed him to overcome his fear of failure through the ability to record his drawing and his voice in private and delete and redo his work if he was unhappy with it. After using the iPad apps, he began to be seen in a different light by his educators and peers. Rather than a virtually nonverbal, disruptive student, he began to be seen as a creative student who had a positive voice in the classroom. One of his classroom educators describes her observations of Connor: 
With Connor, I noticed that it gave him the self-confidence, it gave him the ability to have a voice and to be able to be creative and problem solve in his way.... although he has autism, one of the things I realized with him was that he was so afraid to do something, he was afraid of failure...[with the app] he can just delete and start over again. It was his ability to tell stories. So when he has drawn a picture he'll add the words to it and you can see his face, he's beaming because now he has a voice. He has something that he can actually show us, show his ability to move forward. (Kindergarten educator, June 2017)

The open-ended iPad app supported his areas of challenge, including speaking on the spot and communicating his ideas clearly. It allowed him to share his ideas in a creative and productive way, and to have a positive voice in the classroom.

As the previous examples have shown, the open-ended iPad apps served as tools for integrating children with SLNs into the rest of the class in a similar way as they did for ELLs. This was the third way that the iPad apps supported children with a range of special learning needs. For example, Eric, a child with a learning and speech delay, used the open-ended iPad apps to document his interest in trains and to draw other children to him. With the support of a member of the research team, he took the photo below of a train he had made out of magnetic tiles. He then traced over the photo using a drawing tool:

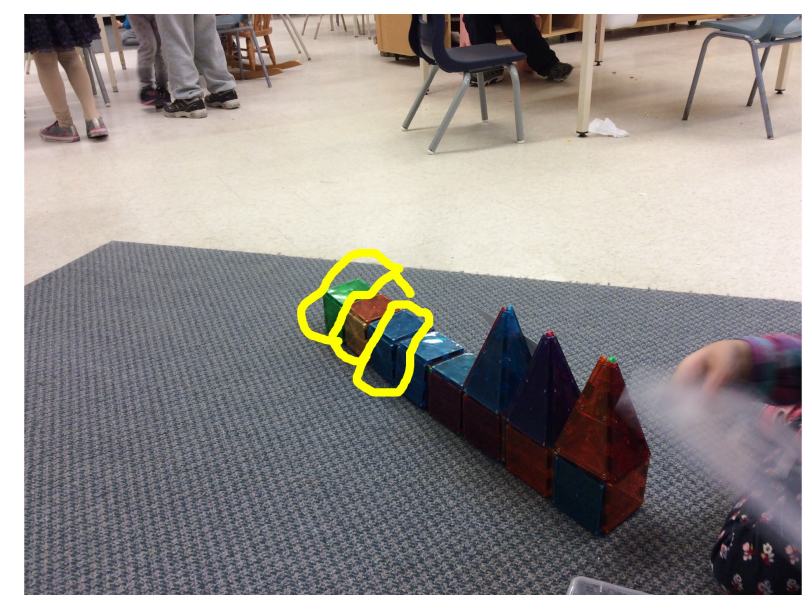

Fig. 5: Train made from magnetic tiles

The research team member then began to videotape Eric in "selfie" mode so that he could watch the video as he continued to build his train. She then played the video back to him and he stopped building and smiled, pointing to his creation in the video and saying "train!" Another child came over as he was building and they worked together taking turns building and recording each other. Previous to this, Eric has been building trains alone and had not attracted the attention of other children. However, the act of building, then documenting and viewing his work on the iPad, drew another child into the play episode with him. 


\section{Barrier or Bridge?}

At first, some of the educators in the kindergarten classrooms worried that the iPads were creating a barrier between the children who were ELLs or had SLNs and the rest of the classroom. They worried when they saw these children off on their own with an iPad. But over time, they began to see that the open-ended iPad apps were providing children with a bridge to full integration in the classroom. The iPad apps contained the tools and autonomy they needed to think through and practice what they wanted to express, in ways that worked for them. The children then either presented their products to their educators and peers or simply archived their work on the iPad. This was not only true of these two groups of children, but also for children who were shy. As one educator explained,

I think [the iPad app project] has been really effective. There are a lot of quiet kids that we have in the class that wouldn't always come and tell you and be enthusiastic about what they've done. And then you realize that they've made a six-minute long recording about something they've made - and with excitement. And all these words that you are like, 'Oh okay, so you do talk about your stuff a lot'. But sometimes I guess maybe being by themselves with the iPad they are a little more confident than talking in front of everybody else as a whole group. (Kindergarten educator, June 2017)

\section{Pedagogical Strategies}

When the kindergarten educators first began to use the open-ended iPad apps in their classrooms, they experienced a number of challenges ranging from technical (e.g., learning to use the iPad and apps), to structural (e.g., WIFI issues, shortage of electrical outlets and secure storage), and pedagogical (e.g., when and how to incorporate the iPad apps into the program). Over the first six to eight weeks, they developed a variety of strategies to manage these challenges, including pedagogical strategies to support the kindergarten students in their use of the open-ended iPad apps. The pedagogical strategies applied to all children in the classrooms, but were particularly important for ELLs and children with SLNs. As mentioned earlier, the kindergarten program in Ontario is play-based and focused on inquiry learning. All of the classrooms had large blocks of time during which the children could choose from a number of activities in the classroom. Some popular activities were building with large or small blocks, dramatic play, and art activities. The iPads were most often used during these play periods. Early in the first year of the study, the educators established routines for the students' use of the iPads. For example, the educators wrote a third of the children's names on each of the three classroom iPads and left them out on a table or low counter for the children to access. The children knew which iPad contained their archived slideshows and they were able to access them independently. Children could either work alone or collaboratively with peers to document their work and their thinking in any way they chose.

Strategies for extending thinking and descriptive language. The kindergarten educators encouraged the children to document their work on the iPads visually, through photos or drawings, and then to audiorecord descriptions and explanations of their work. Initially, many children created drawings or took photographs of their work without including audio recordings. Later, they added simple descriptions. With practice, guidance, and modeling, they began to give more detailed descriptions of their creations 
Monica McGlynn-Stewart, Leah Brathwaite, Lisa Hobman, Nicola Maguire, Emma Mogyorodi, and Yeh Uhn Park

and began to discuss the process of their creation. As one educator explained at the end of the second year of the study:

I think a lot of them just learned how to explain their thinking. Because at the beginning of the year it was a lot of "my brain told me" or "I did it because I wanted to". Whereas now, if they show a picture or a video they say, "I used a square here" or "The tower kept falling down but I fixed it". A lot more detail comes out of it when they share that picture on the iPad than when they write about it or when we are just standing around it talking. (Kindergarten educator, June 2017)

The educators helped the students to achieve this more sophisticated level of description and analysis through informally interviewing the children about their work and suggesting that they audio-record their answers. Another educator explained how this worked in her classroom:

If I see someone next to me recording, I will ask questions and that will extend what they are recording about. Instead of them just saying, "I made a train", I will go further and ask them, "What kinds of shapes do you see in your train?" and, "How many blocks did you use?" (Kindergarten educator, June 2017)

Over time, the children began to take on the role of interviewer that was modeled by the educators. They began to ask each other to expand on their descriptions, as one educator explained, "We are giving the responsibility to the kids. So one of the kids will take [the iPad] and they will interview the child who has made that creation like we had modelled it" (Kindergarten educator, June 2017). Another educator remarked on how some of even the youngest children became proficient interviewers:

There was one [four-year old] student who was a very confident speaker. He would ask another student, "What made you think of this idea?" or "Can you describe that?", "I can't hear you. Can you talk louder?" So things like that. I said, "Jason, you've been listening to what we've been asking you." (Kindergarten educator, June 2017)

Strategies to support peer learning, teaching, and sharing. Another effective pedagogical strategy used in the kindergarten classes was the encouragement of collaborative learning and peer teaching. In the first year of the study, all of the children, both the four-year olds and the five-year olds, were learning about the iPad apps at the same time. However, some had experience with iPads at home and therefore quickly became independent users. Others had a particular interest and aptitude for the iPads and this led to early proficiency. The educators were quick to encourage the more adept students to teach their peers how to use the apps and to work collaboratively with peers on projects of joint interest. By the second year of the study, the five-year olds (senior kindergarten or SK) had a year of work on the apps under their belts and were able to introduce the four-year olds (junior kindergarten or JK) to the apps. This not only cut down on the educators' workload, but it also proved to be more effective. As one educator explains below, learning from a peer was seen to be more "authentic":

And they've become very independent. Because when they work in groups sometimes, the SKs take the leadership to teach the JKs what they can do - instead of us. And I think getting that information from their peers is way more authentic then when they get it from us. So it is neat to see how they are interacting with that device. (Kindergarten educator, June 2017)

210 | LEARNing Landscapes | Autumn 2017, Vol. 11 No. 1 
As mentioned earlier, some children were eager to show their digital creations to the educators and the whole class, while other children were more reluctant to share their work. The latter case was particularly true for many children who were ELL or had SLNs. In order to accommodate both the confident children and the reluctant children, many educators began having an iPad sharing time as part of their wholegroup activities. The children could sign up for the day that they wished to share their work. This helped the children who were eager to share by assuring them that a time had been set aside for them. For the more reluctant children, the list encouraged them to prepare a digital slideshow ahead of time. Many of these children were pleased to be involved in sharing time and were confident to share the slides that they had prepared when they were given advanced warning and time to prepare. For some children, this prerecorded digital sharing led to a greater willingness to share in "real time," unmediated by the iPad.

\section{Discussion}

Fears that digital technology (DT) use may lead young children to become sedentary, passive, and unsociable are common in some of the literature on the subject (e.g., NAEYC, 2012; Radesky et al., 2015, Council on Communication and Media, 2016). These same research studies and many others, however, also mention the potential for DT to enhance children's learning and development. In this study, the fears about DT and young children were not realized, but the potential for enhanced learning opportunities was. The use of open-ended iPad apps in 14 play-based kindergartens led to active and interactive use by the kindergarten children. The iPads provided the children with tools to collaborate with peers, document their inquiries, and deepen and extend their communication. The tools provided by the iPads and the apps 30 Hands and Explain Everything were particularly effective in supporting the needs of English Language Learners (ELLs) and children with special learning needs (SLNs).

In keeping with recent research investigating iPad apps for young children in educational settings (e.g., Falloon \& Khoo, 2014; Fleer, 2014; Herro, 2015; Rowsell \& Harwood, 2015), the findings of this study illustrate that iPad apps can support literacy learning for young children. The expanded modes available on the iPad (photo, video, audio, text, etc.) were motivating for children and supported them as they explored and documented their interests, as suggested by Rowsell (2017). The children in this study exhibited a wide range of oral literacy skills including planning, describing, analyzing, explaining, co-ordinating, presenting, teaching, storytelling, and singing. Their visual literacy skills were no less wide ranging and included taking photos and videos of themselves and others, of the indoor and outdoor environments, and of their own creations. They also drew on blank slides using a variety of drawing tools and made use of the background scenes in the apps. Moreover, they often embellished the backgrounds and their photos by drawing over them. They incorporated text into their slideshows in the form of letters drawn by hand or through the use of the keyboard. The children often combined two or more of these literacy skills in their documentation, demonstrating considerable digital skills. The open-ended nature of the apps used in the study 
allowed for children at different levels of English language proficiency and different levels of literacy learning to effectively engage in meaning making using a variety of literacy skills.

For children with SLNs, use of the iPad apps increased the ease and amount of their communication, as Flores et al. (2012) found in their study. Moreover, they were more engaged with learning and created more complex literacy output as described by Oakley et al. (2013). The multiple modes available in the iPad apps allowed children in this study to use the mode that best suited their abilities (visual, auditory, text, etc.) and to overcome barriers that traditional literacy tools and approaches such as paper and pencil or face-to-face spontaneous conversation may have caused. Children who were ELL used the iPad apps to communicate in their home languages, an important literacy practice (Rodriguez, 2010), as well as to practice their English language skills.

For both ELLs and children with SLNs, the open-ended iPad apps provided them with the ability to privately practice their communication, and to erase and redo it if desired. This allowed them to build the skills and confidence they needed to share their work with their educators and peers. It also led to a greater integration of these children with the rest of the class. Students at different levels of English proficiency and with different levels of literary accomplishment were able to collaborate using the iPad apps. Students learned about each other's interests and abilities through the use of the apps, and were able to make use of this information to collaboratively construct digital documentation of their thinking.

For the kindergarten educators, the open-ended iPad apps provided a vehicle to learn about the interests and abilities of children who were ELLs or who had SLNs. For those students who were not yet proficient in English or in the use of traditional learning tools, the apps provided other ways for the educators to acquire the information they needed to support their continued learning. The apps also proved to be effective tools for drawing out shy or reluctant learners, as well as for helping other children to focus and extend their thinking. In addition to providing support for literacy learning and development, the educators found the apps supported them to integrate collaboration, creativity, and digital learning into their programs.

\section{Conclusion}

The findings from this study strongly suggest that open-ended iPad apps, when used in a play-based program, can support the literacy learning of all children, but can be particularly effective for children who are ELL and who have SLNs. The success of the iPad apps in supporting literacy in these kindergarten programs may be due to a number of factors. It is important to note that the iPad apps were not used to teach specific literacy skills, or to act as behaviour management tools (i.e., to calm children down or as a reward), but as a way to support children to document their work and their world. The children were encouraged to follow their interests, express their creativity, and to work collaboratively, and they were given large blocks of time to do so.

The educators supported the children's use of the iPad apps through a number of pedagogical strategies that were neither overly structured, nor were they completely hands-off. They sought to expand and 
deepen their students' thinking and communication through providing effective routines, thoughtful questions, and meaningful opportunities to collaborate and share their work with peers. The educators, in turn, were supported by the research team as they learned how to use the iPads and apps, and how to integrate them into their programs. The educators repeatedly expressed how essential this ongoing support was as they developed the technical and pedagogical strategies they needed to effectively employ the apps in their classrooms. It appears that it was the combination of these factors that led to the active, engaged, creative, and collaborative literacy experiences that occurred in the classrooms in this study.

\section{References}

Blagojevic, B., Brumer, H., Chevalier, S., O'Clair, A., \& Thomes, K. (2012). Touch and grow: Learning and exploring using tablets. Teaching Young Children, 6(1), 18-21.

Burnett, C., Merchant, G., Pahl, K., \& Rowsell, J. (2014). The (im)materiality of literacy: The significance of subjectivity to new literacies research. Discourse: Studies in the Cultural Policies of Education, 35(1), 90-103.

Council on Communications \& Media. (2016). Media and young minds. Pediatrics, 138(5).

Falloon, G., \& Khoo, E. (2014). Exploring young students' talk in iPad-supported collaborative learning environments. Computers \& Education, 77, 13-28.

Retrieved from http://dx.doi.org/10.1016/j.compedu.2014.04.008

Fleer, M. (2014). The demands and motives afforded through digital play in early childhood activity settings. Learning, Culture and Social Interaction, 3, 202-209.

Flores, M., Musgrave, K., Renner, S., Hinton, V., Strozier, S., Franklin, S., \& Hill, D. (2012). A comparison of communication using the apple iPad and a picture-based system. Augmentative and Alternative Communication, 28(2), 74-85. doi:10.3109/07434618.2011.644579

Gee, J. P. (2005). Good video games and good learning. Phi Kappa Phi Forum, 85(2), 34-37.

Herro, D. (2015). Sustainable innovations: Bringing digital media and emerging technologies to the classroom. Theory Into Practice, 54(2), 117-127.

Kress, G. (1997). Before writing: Rethinking the paths to literacy. New York, NY: Routledge Press.

Lee, T.H., Wu, F. G., \& Chen, H. T. (2017). Innovation \& evaluation of tangible direct manipulation digital drawing pens for children. Applied Ergonomics, 60, 207-219.

MacKey, M. (2011). The embedded and embodied literacies of a young reader. Children's Literature in Education, 42, 289-307.

National Association for the Education of Young Children. (2012). Technology and interactive media as tools in early childhood programs serving children from birth through age 8. A joint position statement of the National Association for the Education of Young Children and the Fred Rogers Center for Early Learning and Children's Media at Saint Vincent College. Retrieved from http://www.naeyc.org/files/naeyc/PS_technology_WEB.pdf 
Monica McGlynn-Stewart, Leah Brathwaite, Lisa Hobman, Nicola Maguire, Emma Mogyorodi, and Yeh Uhn Park

Neumann, M. M. (2016). Young children's use of touch screen tablets for writing and reading at home: Relationships with emergent literacy. Computers \& Education, 97, 61-68. doi:10.1016/j.compedu.2016.02.013

Nicoladis, E., Charbonnier, M., \& Popescu, A. (2016). Second language/bilingualism at an early age with emphasis on its impact on early socio-cognitive and socio-emotional development. In R. Tremblay, M. Boivin, and R. Peters (Eds.), Encyclopedia on Early Childhood Development. Retrieved from http://www.child-encyclopedia.com/second-language/according-experts/second-languagebilingualismearly-age-emphasis-its-impact-early

Oakley, G., Howitt, C., Garwood, R., \& Durack, A. (2013). Becoming multimodal authors: Preservice teachers' interventions to support young children with autism. Australasion Journal of Early Childhood, 38(3), 86-96.

Ontario Ministry of Education. (2016). The kindergarten program 2016. Toronto, Ontario: Author.

Radesky, J. S., Schumacher, J., \& Zuckerman, B. (2015). Mobile and interactive media use by young children: The good, the bad, and the unknown. Pediatrics, 135(1), 1-3. doi:10.1542/peds.2014-2251

Rodriguez, V. (2010). Pathways to bilingualism: Young children's home experiences learning English and Spanish. Early Childhood Research \& Practice, 12(1). Retrieved from http://go.galegroup.com/ps/ i.do? $\mathrm{p}=\mathrm{AONE} \& \mathrm{sw}=\mathrm{w} \& \mathrm{u}=$ toro $15002 \& \mathrm{v}=2.1 \& \mathrm{id}=\mathrm{GALE} \% 7 \mathrm{CA} 227012751 \& \mathrm{it}=\mathrm{r} \& \mathrm{asid}=1 \mathrm{a} 5 \mathrm{~b} 330 \mathrm{ba} 55446$ c6a031bc88d0e257aa

Rowsell, J. (2017). Be the ' $\mathrm{I}$ ' in iPad: iPads and the children who love them. In D. Harwood (Ed.), Crayons and iPads: Learning and teaching of young children in the digital world (pp. 6-15). Thousand Oaks, CA: Sage.

Rowsell, J., \& Harwood, D. (2015). "Let It Go": Exploring the image of the child as a producer, consumer, and inventor. Theory Into Practice, 54, 136-146. doi:10.1080/00405841.2015.1010847

UNESCO. (2011). Enhancing learning of children from diverse language backgrounds: Mother tongue based bilingual or multilingual education in the early years. France: United Nations Educational, Scientific and Cultural Organization.

Retrieved from http://unesdoc.unesco.org/images/0021/002122/212270e.pdf

Wimmer, J. J., Skramstad, E., \& Khan, I. (2012). Incorporating, utilizing, and manipulating new literacies in the classroom. The Educational Forum, 76, 438-441.

Wong, S. S. (2015). Mobile digital devices and preschoolers' home multiliteracy practices. Language and Literacy, 17(2), 75-90.

Yilmaz, R.M. (2016). Educational magic toys developed with augmented reality technology for early childhood education. Computers in Human Behaviour, 54, 240-248. doi:10.1016/j.chb.2015.07.040. 


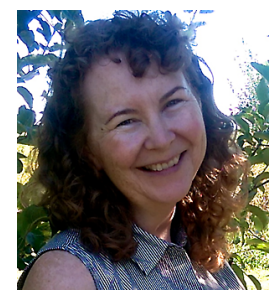

Monica McGlynn-Stewart (PhD) is a Professor in the School of Early Childhood at George Brown College, Toronto, Ontario. She teaches courses in curriculum, policy, and research methods. She is a former elementary teacher, principal, and consultant. Currently, she is the Principal Investigator on the federally funded research project, Toys or Tools? Using Tablet Applications for Open-Ended Literacy Learning. Her research interests include teacher action research, student engagement, literacy learning and teaching in the early years, and digital technology mediated learning and teaching.

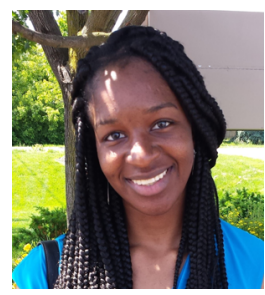

Leah Brathwaite is a fourth-year student in the Early Childhood Leadership degree program at George Brown College. She has a background in computer technology, and works part-time as an Early Childhood Assistant to children from Kindergarten to grade 7 . She is currently a Student Researcher on the federally funded research project, Toys or Tools? Using Tablet Applications for Open-Ended Literacy Learning. Her research interests include early childhood program quality, literacy learning in the early years, and digital technology use in the early years.

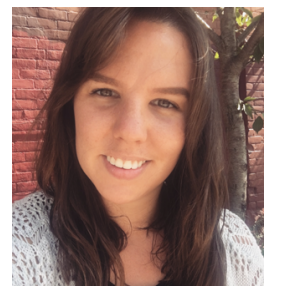

Lisa Hobman is currently working with the YMCA of the Greater Toronto Area as a Registered Early Childhood Educator (RECE). She has been involved with the Toys or Tools? project since the beginning and hopes to continue studying the impact of technology on early years pedagogy in a master's program in the near future.

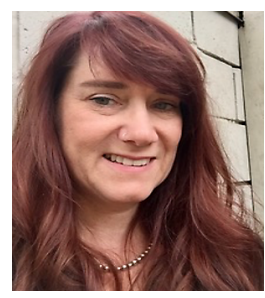

Nicola Maguire (MA) is a part-time faculty member in the School of Early Childhood at George Brown College and a Research Assistant on the federally funded research project, Toys or Tools? Using Tablet Applications for Open-Ended Literacy Learning. She also supports students in school settings with their use of assistive technology devices. Her research interests include children's outdoor play, digital technology uses for learning and teaching, and arts-based curriculums.

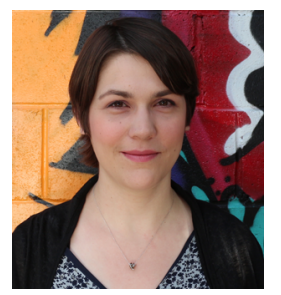

Emma Mogyorodi (B. ECL, RECE) is a graduate student at Ryerson University. She also teaches an early childhood musicianship class in Toronto. She previously served as the Early Childhood Music Coordinator at The Royal Conservatory. In addition to her studies and teaching, she works as a Research Assistant for Toys or Tools? Using Tablet Applications for Open-Ended Literacy Learning under the supervision of Dr. Monica McGlynn-Stewart. Her research interests include digital technology, literacy learning, and music education. 
Monica McGlynn-Stewart, Leah Brathwaite, Lisa Hobman, Nicola Maguire, Emma Mogyorodi, and Yeh Uhn Park

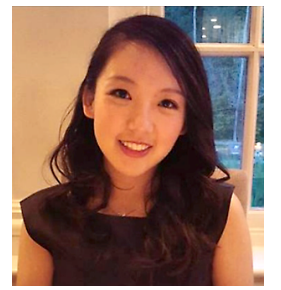

Yeh Uhn Park is a fourth-year student in the Early Childhood Leadership degree program at George Brown College. She was a Research Assistant on the project, Designing family-play activities for an online learning platform in 2016. During 20162017, Park was a Research Assistant on the Toys or Tools? research project. Her research interests include children's early multilingual learning, literacy learning, parental support, and digital technology. 